\title{
Verticillium dahliae VdTHI20, Involved in Pyrimidine Biosynthesis, Is Required for DNA Repair Functions and Pathogenicity
}

\author{
Tengfei Qin ${ }^{1, \dagger}{ }^{\dagger}$ Wei Hao ${ }^{2, \dagger}$, Runrun Sun ${ }^{1}$, Yuqing Li ${ }^{1}$, Yuanyuan Wang ${ }^{1}$, Chunyan Wei ${ }^{1}$, \\ Tao Dong ${ }^{1}$, Bingjie $\mathrm{Wu}^{3}$, Na Dong ${ }^{1}$, Weipeng Wang ${ }^{1}$, Jialiang Sun ${ }^{1}$, Qiuyue Yang ${ }^{1}$, \\ Yaxin Zhang ${ }^{1}$, Song Yang ${ }^{1}$ and Qinglian Wang ${ }^{1, *}$ \\ 1 Henan Collaborative Innovation Center of Modern Biological Breeding, Henan Institute of Sciences and \\ Technology, Xinxiang 453003, China; qintengfeisam@gmail.com (T.Q.); sunrunrun123@gmail.com (R.S.); \\ lyq120327@gmail.com (Y.L.); wangyy1007@gmail.com (Y.W.); chunyanwei688@gmail.com (C.W.); \\ dongtao109@gmail.com (T.D.); dongnana1229@gmail.com (N.D.); wweipeng125@gmail.com (W.W.); \\ swj15845@gmail.com (J.S.); yqiuyue0127@gmail.com (Q.Y.); yaxinzhang33@gmail.com (Y.Z.); \\ yangsong11223@gmail.com (S.Y.) \\ 2 School of Life Sciences, The Chinese University of Hong Kong, Hong Kong 999077, China; \\ haowei9111@gmail.com \\ 3 College of Agriculture, Liaocheng University, Liaocheng 252059, China; wubingjie@lcu.edu.cn \\ * Correspondence: wangqinglian666@gmail.com \\ + These authors contributed equally to this work.
}

Received: 22 December 2019; Accepted: 15 February 2020; Published: 18 February 2020 updates

\begin{abstract}
Verticillium dahliae (V. dahliae) infects roots and colonizes the vascular vessels of host plants, significantly reducing the economic yield of cotton and other crops. In this study, the protein VdTHI20, which is involved in the thiamine biosynthesis pathway, was characterized by knocking out the corresponding VdTHI20 gene in $V$. dahliae via Agrobacterium tumefaciens-mediated transformation (ATMT). The deletion of $V d T H I 20$ resulted in several phenotypic defects in vegetative growth and conidiation and in impaired virulence in tobacco seedlings. We show that VdTHI20 increases the tolerance of $V$. dahliae to UV damage. The impaired vegetative growth of $\Delta V d T H I 20$ mutant strains was restored by complementation with a functional copy of the VdTHI20 gene or by supplementation with additional thiamine. Furthermore, the root infection and colonization of the $\Delta V d T H I 20$ mutant strains were suppressed, as indicated by green fluorescent protein (GFP)-labelling under microscope observation. When the RNAi constructs of VdTHI20 were used to transform Nicotiana benthamiana, the transgenic lines expressing dsVdTHI20 showed elevated resistance to $V$. dahliae. Together, these results suggest that VdTHI20 plays a significant role in the pathogenicity of $V$. dahliae. In addition, the pathogenesis-related gene VdTHI20 exhibits potential for controlling V. dahliae in important crops.
\end{abstract}

Keywords: Verticillium dahliae; THI20; thiamine biosynthesis; pathogenicity

\section{Introduction}

The soilborne phytopathogen Verticillium dahliae causes vascular wilt diseases, which devastatingly attacks many important crops [1,2]. A severe loss in the yield of cotton results from verticillium wilt in China every year, causing severe economic losses in the cotton industry [3,4]. Until very recently, no effective fungicide could cure this damaging disease because the hyphae of $V$. dahliae spread inside the xylem tissues, where they cannot be reached by fungicides [5]. The molecular mechanisms underlying the pathogenesis of this fungus remain unknown. Thus, studying growthand virulence-related genes is of great importance for controlling this fungus. 
$V$. dahliae can remain dormant in soil and dead plants for many years and invade the roots of nearby host plants. Hyphae adhere to and penetrate plant roots and then grow into the vascular system. With abundant budding and growth, the transportation of nutrients in the host is prevented, leading to various symptoms, including stunting, vascular browning, wilting, and foliar chlorosis and necrosis. Finally, the fungus completes its life cycle after its release into the soil [6]. Thiamine, or water-soluble vitamin B, a vital metabolic enzyme, acts as a cofactor in amino acid and carbohydrate metabolism in all living organisms [7]. Only microorganisms and plants can synthesize thiamine naturally, whereas animals cannot. Thiamine also plays a vital role in different fungal life cycles, such as growth, development, sporulation and host invasion.

Thiamine consists of two aromatic components, a pyrimidine (2-methyl-4-amino-5hydroxymethylpyrimidine, HMP) and a thiazole (4-methyl-5- $\beta$-hydroxyethylthiazole, HET), which are synthesized in independent branches of the thiamine synthesis pathway. Thiamine pyrophosphate, phosphorylated thiamine (TPP), is the predominant active form of thiamine [8,9]. In Saccharomyces cerevisiae, many genes were found to be involved in thiamine pathway. THI5, THI11, THI12, and THI13 are THI5 gene family members that their function is redundant in HMP-P synthesis [10]. Three members of the THI20 family proteins, THI20/21/22, were characterized in S. cerevisiae [11]. THI20 and THI21 are two redundant genes that encode the HMP-P kinase of S. cerevisiae. THI20/THI21 can not only phosphorylate HMP to HMP-P but also phosphorylate HMP-P to HMP-PP [12]. Moreover, THI20 has been indicated to be a trifunctional protein with both thiamine biosynthetic and degradative activity [13]. THI4, involved in HET-P synthesis in S. cerevisiae, could play a role in DNA damage tolerance [14]. THI6 has been showed to have the thiamin-phosphate pyrophosphorylase and hydroxyethylthiazole kinase activity [15]. THI80 is a thiamin-pyrophosphokinase gene that catalyzes thiamine to the active form (TPP) [16]. THI10, which encodes a thiamine transport protein that transports the thiamine from periplasm to the cell [17]. $\mathrm{PHO} 3$ is a periplasmic acid phosphatase that allows thiamin phosphates hydrolysis in periplasm [18]. In recent years, several genes in the thiamine biosynthesis pathway have been found in $V$. dahliae. VdTHI4, involved in HET-P synthesis, is required for fungal induction in tomato, as demonstrated by the infection analysis of the knockout strain $\triangle V d T H I 4$ [19]. VdThit, a thiamine transport protein, is important for the pathogenicity of $V$. dahliae, as supported by infection assays with the $V$. dahliae $V d \Delta T H i t$ deletion strain (Table 1) [20]. HET biosynthesis and thiamine transport for the thiamine biosynthesis pathway seem to influence the virulence and pathogenesis of V. dahlia. Only one THI20 family gene, VdTHI20, was found in V. dahliae (Figure 1). However, the mechanism by which $V d T H I 20$ contributes to the virulence and pathogenesis of $V$. dahliae has not been reported.

Table 1. Genes involved in thiamine biosynthesis.

\begin{tabular}{ccc}
\hline Gene & Protein Function & References \\
\hline THI4 & HET-P synthesis; Stress response and DNA repair & {$[14,19]$} \\
THI5/THI1/THI12/THI13 & HMP-P synthesis & {$[10]$} \\
THI6 & Thiamin-phosphate pyrophosphorylase and & {$[15]$} \\
THI10 & hydroxyethylthiazole kinase & {$[17]$} \\
THI20 & Thiamine transport protein & {$[11,12,21]$} \\
THI21/THI22 & HMP-PP synthesis and thiamine degradation & {$[11,12]$} \\
THI80 & HMP-PP synthesis & {$[16]$} \\
VdThit & Thiamin pyrophosphokinase & {$[20]$} \\
PHO3 & Thiamine transport protein; Vegetable growth, & {$[18]$} \\
\hline
\end{tabular}




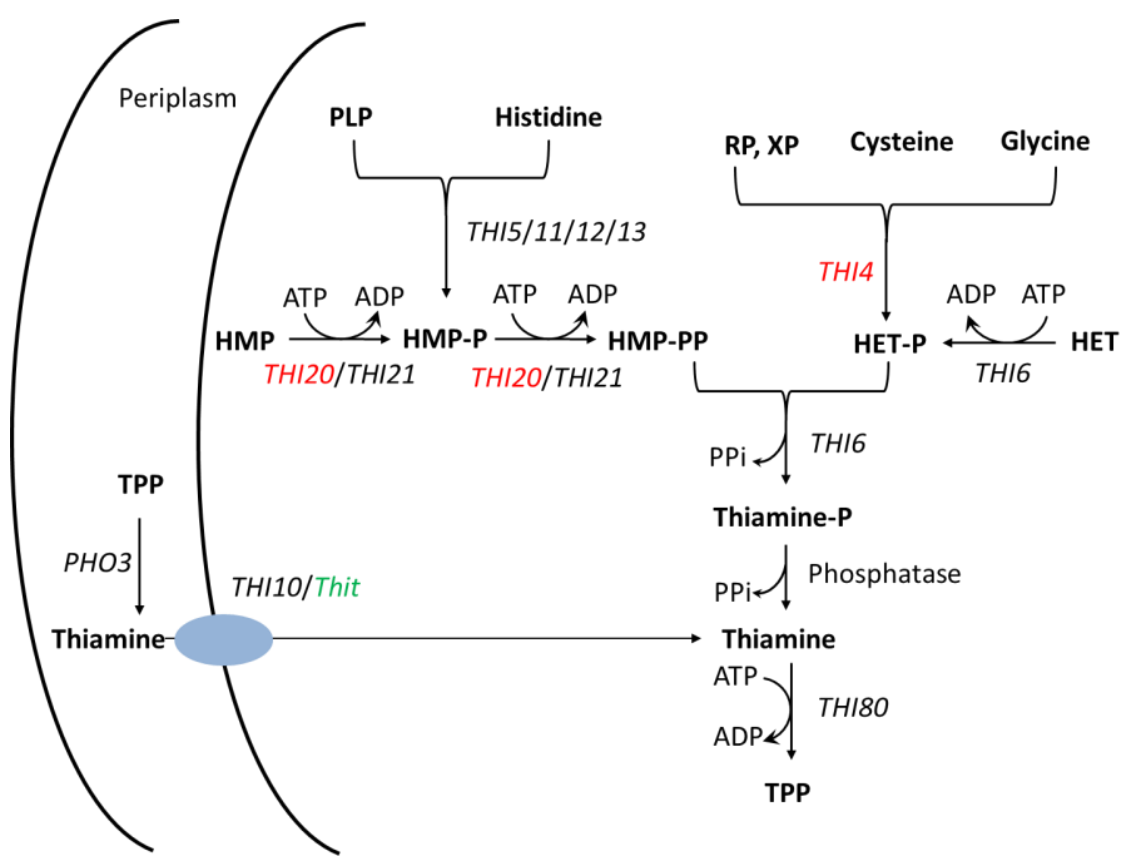

Figure 1. A schematic of the thiamine biosynthesis pathway. Black italics represent the genes found in S. cerevisiae. Green italics represent the genes found in $V$. dahliae. Red italics indicate genes found in both $S$. cerevisiae and $V$. dahliae. Blue oval represents thiamine transport protein.

In the present study, we generated a targeted VdTHI20 (VDAG_05690) mutant, $\Delta V d T H I 20$. We characterized its growth, development, stress tolerance, penetration ability and virulence in Nicotiana benthamiana. Decreased colony growth was detected as a result of the deletion of VdTHI2O. The virulence of the mutants was significantly decreased compared with that of the wild-type and complemented strains. The germination of $\triangle V d T H I 20$ was significantly impaired, as determined by confocal microscopy observations. Furthermore, transgenic N. benthamiana expressing dsVdTHI20 exhibited resistance to $V$. dahliae. Overall, our results indicate that $V d T H I 20$ plays a critical role in the pathogenicity of $V$. dahliae.

\section{Results}

\subsection{Deletion and Complementation of VdTHI20 in V. dahliae}

The VdTHI20 gene was replaced with a geneticin-resistance cassette (neo) via homologous recombination in $V d$ - $w t$. Neomycin-resistant transformants were verified by genomic PCR. Physical maps of the VdTHI2O locus and of the homologous recombination constructs were obtained by fusion of the VdTHI20 up flank, a neo resistance gene cassette and VdTHI20 down flank (Figure 2A). The VdTHI20 gene was successfully replaced in 6 out of 210 analysed transformants. Two $\Delta V d T H I 20$ mutants ( $\triangle V d T H I 20-2$ and $\triangle V d T H I 20-6$ ) were selected for further analysis (Figure 2B). Moreover, a functional copy of $V d T H I 20$ was introduced into $\triangle V d T H I 20-2$ and $\triangle V d T H I 20-6$ for complementation, resulting in two complemented strains, $\Delta V d T H I 20-2-c$ and $\Delta V d T H I 20-6-c$. Successful transformation was confirmed by genomic PCR with the primers hyg-F/hyg-R and THI20-F/THI20-R (Figure 2C). $\triangle$ VdTHI20-2-C and $\triangle V d T H I 20-6-C$ were selected for further phenotypic observations. 


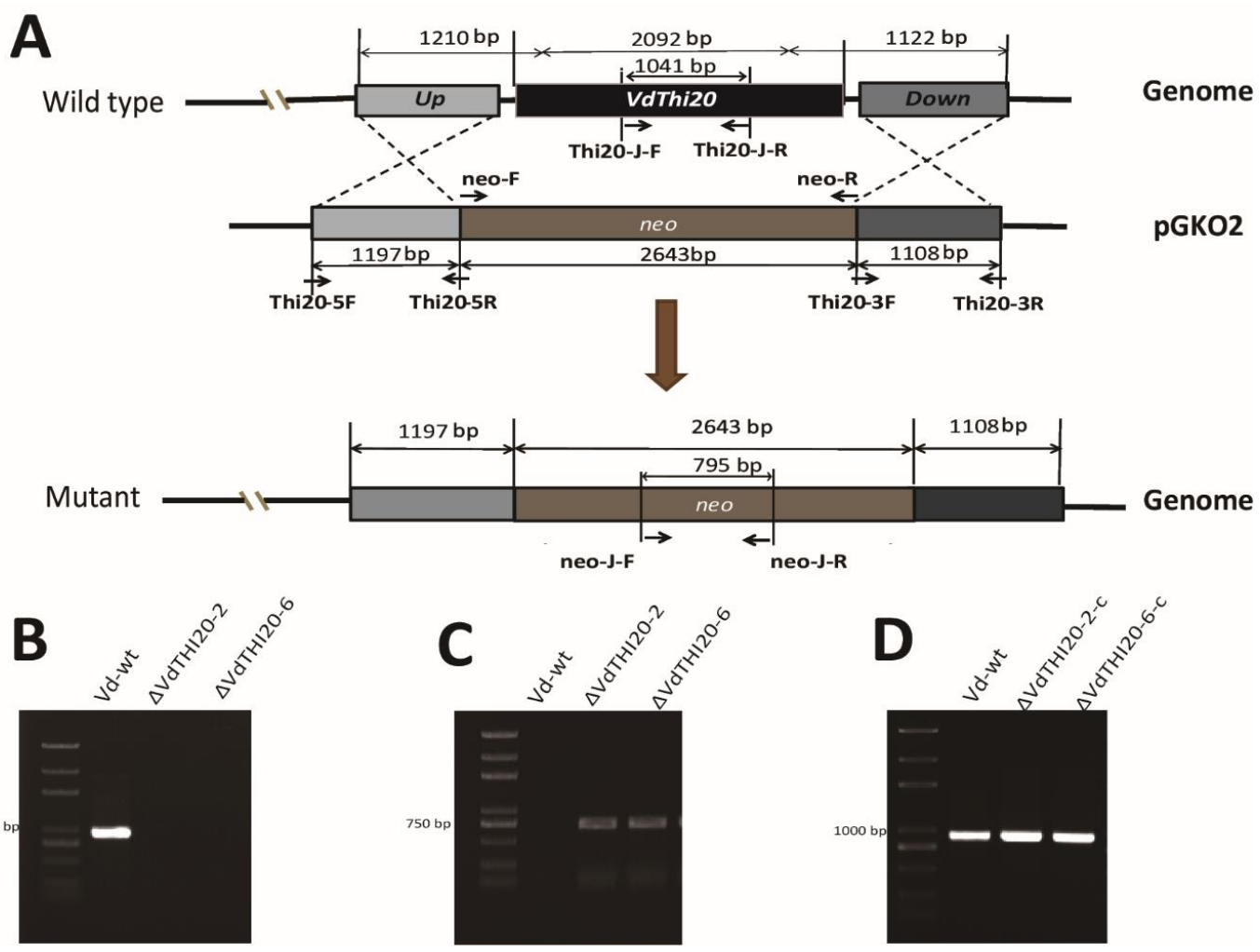

Figure 2. Schematic of the VdTHI20 gene knock out vector design and complemented $\Delta V d T H I 20$ mutant strains. (A) Construction scheme designed for the VdTHI20 gene knockout vector. VdTHI20 gene deletion was verified by PCR. Genomic DNA of the wild-type $V$. dahliae strain $991(V d-w t)$ and $\Delta V d T H I 20$ mutant strains were amplified with the primer pairs neo-J-F and neo-J-R and THI20-J-F and THI20-J-R. (B) A $1041 \mathrm{bp}$ fragment was amplified from $V d-w t$ using the primer pair THI20-J-F and THI20-J-R. (C) A $795 \mathrm{bp}$ fragment was amplified with the primer pair neo-J-F and neo-J-R from the $V d \Delta T H I 20$ mutant strains. (D) Confirmation of complemented stains ( $\triangle V d T H I 20-2-c$ and $\Delta V d T H I 20-6-c)$ was performed with the primers THI20-J-F and THI20-J-R.

\subsection{Radial Mycelial Growth in $\Delta V d T H I 20$ Mutants Was Significantly Reduced}

The function of $V d T H I 20$ was investigated by growing $V d-w t$, two mutants ( $\triangle V d T H I 20-2$ and $\Delta V d T H I 20-6)$ and two complemented stains ( $\triangle V d T H I 20-2-c$ and $\Delta V d T H I 20-6-c)$ on MM agar with different carbon sources (pectin, sucrose, galactose, xylose or starch). The growth of both the $\triangle V d T H I 20-2$ and $\triangle V d T H I 20-6$ strains was delayed compared with that of $V d-w t$ and both complemented strains (Figure $3 \mathrm{~A}$ ). In addition, the colony diameters of the $\triangle V d T H I 20$ mutants on different carbon sources were smaller than those of $V d-w t$ and the two complemented strains $\Delta V d T H I 20-2-c$ and $\Delta V d T H I 20-6-c$. The colony diameters of the $\Delta V d T H I 20$ mutants on different carbon sources, sucrose, pectin, starch, galactose, and xylose, were reduced to $68.7 \%, 63.23 \%, 69.69 \%, 54.76 \%$, and $59.76 \%$, respectively, of the diameter of $V d$-wt (Figure 3B-F). Similarly, in the $\Delta V d T h i t$ mutant, a disruptant of VdThit, radial mycelial growth was also significantly reduced [20]. These results indicate that $V d T H I 20$ contributes to the hyphal vegetative growth and carbon utilization of $V$. dahliae. 

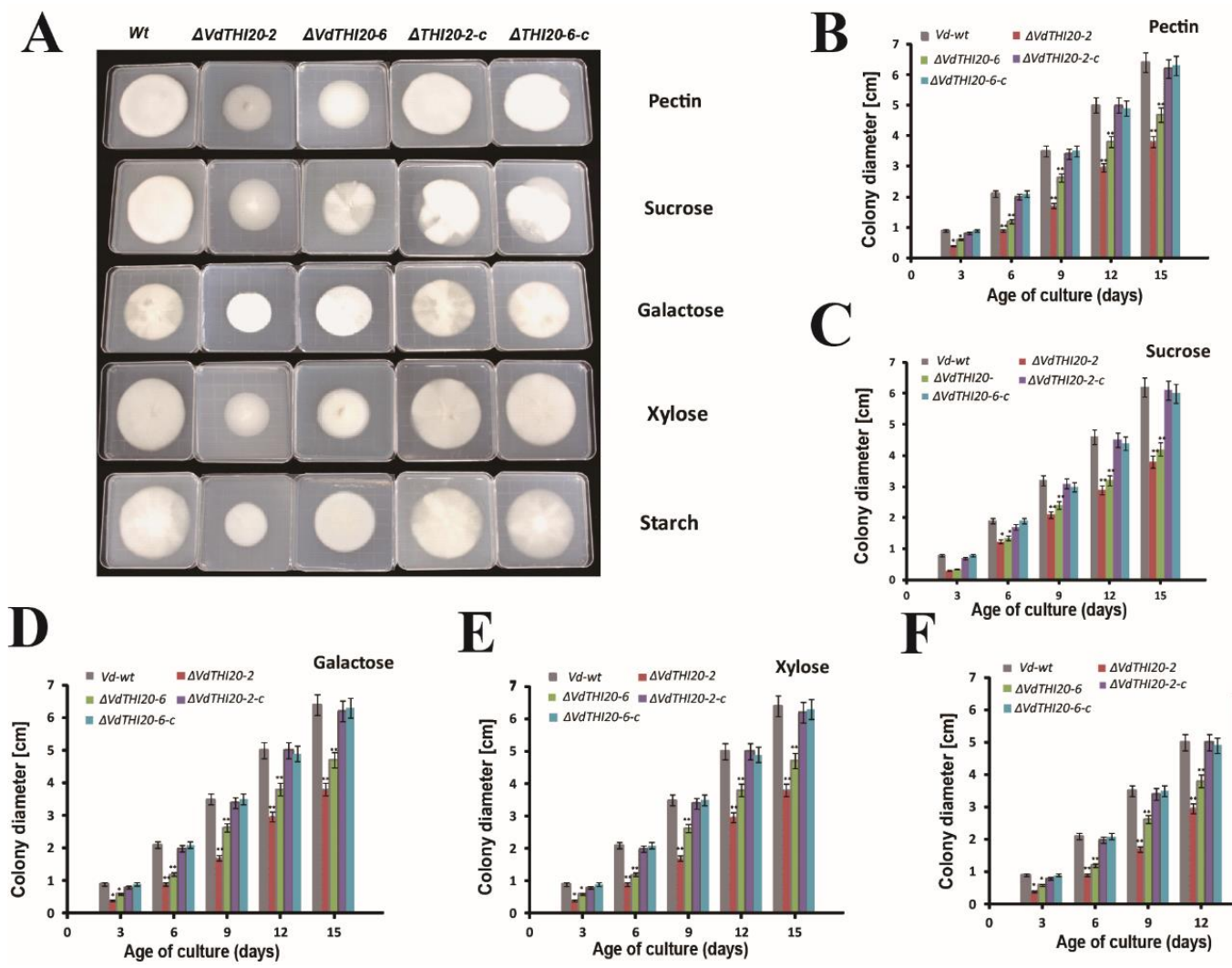

Galactose $\mathrm{C}$

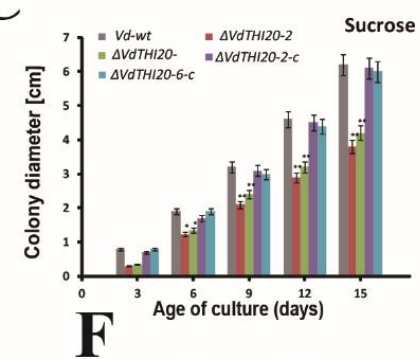

Figure 3. Mycelial growth of the $V d$-wt strain, $\triangle V d T H I 20$ ( $\triangle V d T H I 20-2$ and $\Delta V d T H I 20-6)$ mutant strains, and complemented strains ( $\triangle V d T H I 20-2-c$ and $\Delta V d T H I 20-6-c)$. (A) Colony morphology was observed on MM agar with different carbon sources after 15 days. (B-F) Colony diameters of $V d-w t$ strain, $\triangle V d T H I 20$ mutant strains and complemented strains grown on different carbon sources, sucrose, pectin, starch, galactose, and xylose, respectively. Colony diameters were measured after 3, 6, 9, 12, and 15 days. Values represent the mean \pm standard deviation from three independent replicates. Mycelial growth of the $\Delta V d T H I 20$ mutant strains and the complemented strains on MM agar were compared with $V d$-wt strain. Asterisks $\left({ }^{*}\right)$ indicate significant differences by Student's $t$ test at $P<0.05$. Asterisks $\left({ }^{* *}\right)$ indicate significant differences by Student's $t$ test at $P<0.01$.

\subsection{Exogenous Thiamine Recovered the Hyphal Growth of $\Delta V d T H I 20$ Mutants}

Hyphal growth in the $\Delta V d T H I 20$ mutant strains was slower than that in the $V d$-wt strain and complemented strains ( $\triangle V d T H I 20-2$ and $\Delta V d T H I 20-6)$ according to our previous study. To uncover whether exogenous thiamine could recover the hyphal growth of the $\triangle V d T H I 20$ mutants, MM agar plates were supplied with different concentrations of exogenous thiamine $(0.2 \mathrm{mg} / \mathrm{L}$ to $2 \mathrm{mg} / \mathrm{L})$, and the colony diameters were measured at 4 and 8 days. Hyphal growth was recovered with a high concentration of exogenous thiamine (Figure $4 \mathrm{~A}$ ). This result is similar to previous studies on $\triangle V d T H I 4$ (VdTHI4 involved in HET-P synthesis). We then confirmed the expression level of the $V d T h i t$ gene (encoding thiamine transport protein) in the $V d$-wt strain and $\Delta V d T H I 20$ mutant strains with exogenous thiamine. The expression level of VdThit was significantly higher in the $\Delta V d T H I 20$ mutant strains than in $V d$-wt. Interestingly, the expression level of $V d T h i t$ in the $V d-w t$ strain and $\triangle V d T H I 20$ mutant strains showed no significant difference with different concentrations of exogenous thiamine (Figure 4B). These results suggest that thiamine can enter $V$. dahliae strains through the plasma membrane by simple diffusion and that $V$. dahliae strains can use thiamine in two separate pathways, each of which is indispensable. 

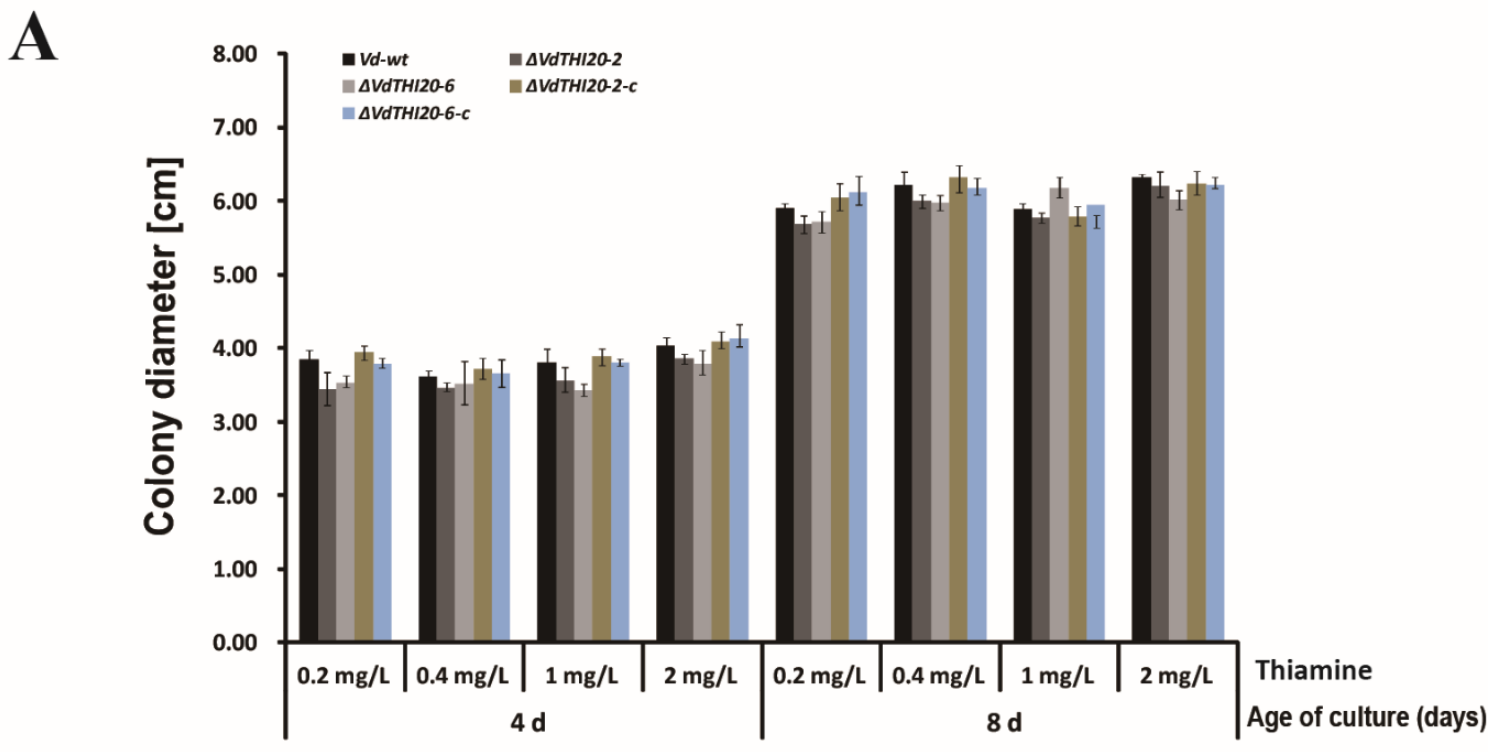

B

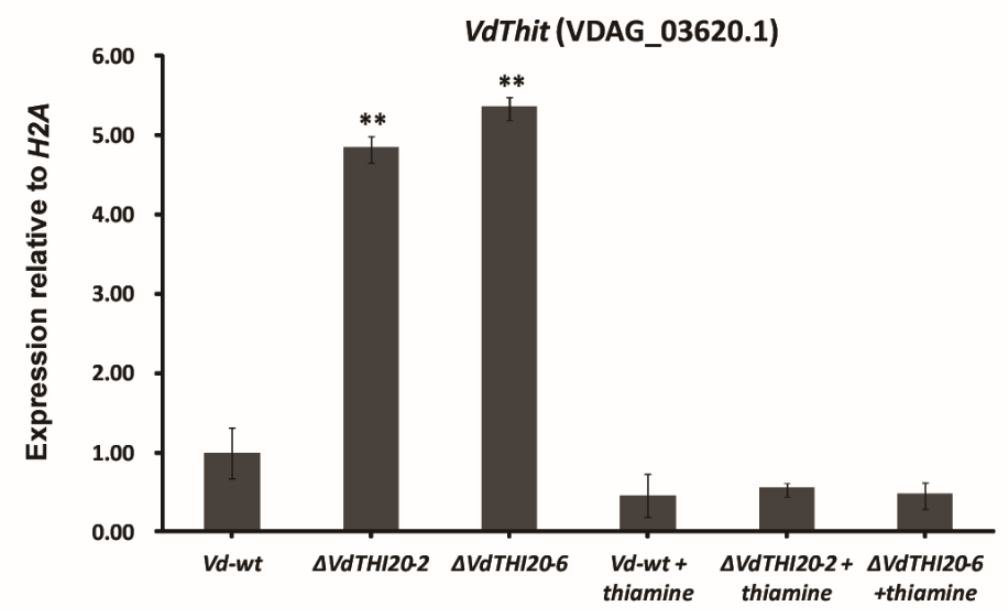

Figure 4. Exogenous thiamine recovered the hyphal growth of $\Delta V d T H I 20$ mutants on Czapek-Dox agar plates. (A) Colony diameters of the $V d$-wt strain, $\Delta V d T H I 20$ mutant strains $(\triangle V d T H I 20-2$ and $\Delta V d T H I 20-6)$, and complemented strains ( $\triangle V d T H I 20-2-c$ and $\Delta V d T H I 20-6-c)$ supplemented with exogenous thiamine $(0.2 \mathrm{mg} / \mathrm{L}$ to $2 \mathrm{mg} / \mathrm{L})$ were measured at $7 \mathrm{dpi}$. (B) The expression of $V d T h i t$ in the $V d$-wt strain and $\Delta V d T H I 20$ mutant strains with or without exogenous thiamine. Values are means \pm standard deviation of three independent experiments performed in duplicate. Asterisks $\left.{ }^{* *}\right)$ indicate significant differences by Student's $t$ test at $P<0.01$.

2.4. Knockout of VdTHI20 Reduced Conidial Germination and Production and Caused Abnormal V. dahliae Hyphal Morphology

When conidia and hyphae were observed with the optical microscope after being cultured for $24 \mathrm{~h}$ after germination in liquid Complete medium (CM) broth, $V d$-wt hyphae displayed radical growth; however, $\triangle V d T H I 20$ hyphae grew slowly and generated swollen and atypical branches (Figure 5A). In addition, the role of $\Delta V d T H I 20$ in conidial germination was analysed. $V d-w t$, the two mutants ( $\Delta V d T H I 20-2$ and $\Delta V d T H I 20-6)$ and the two complemented stains ( $\Delta V d T H I 20-2-c$ and $\Delta V d T H I 20-6-c)$ were incubated in liquid CM for $30 \mathrm{~h}$. The conidial germination of the $\Delta V d T H I 20$ mutants occurred more slowly than that of $V d-w t$ and both complemented stains, $\Delta V d T H I 20-2-c$ and $\Delta V d T H I 20-6-c$. Only approximately $36 \%$ of the conidia of the $\Delta V d T H I 20$ mutant strains germinated, while $90 \%$ of $V d-w t$ conidia and $85 \%$ of the complemented strains conidia germinated (Figure 5B). Additionally, conidia production was studied in all $V$. dahliae strains cultured on Czapek-Dox agar plates. $\Delta V d T H I 20-2$ 
and $\triangle V d T H I 20-6$ produced significantly fewer conidia than $V d-w t$ and the complemented strains (Figure 5C). The results suggest that $V d T H I 20$ participates in conidial germination, conidiation, and mycelial development.

A

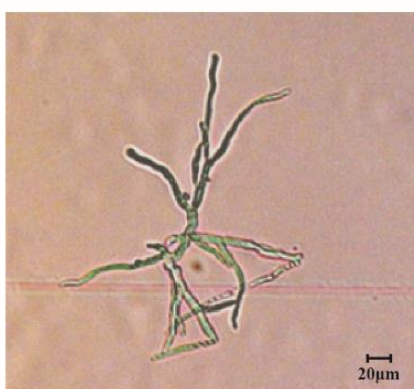

Wt

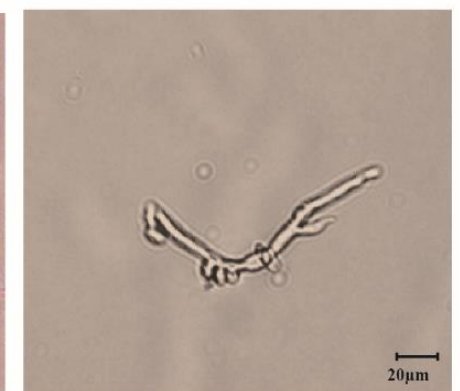

$\Delta V d T H I 20-2$

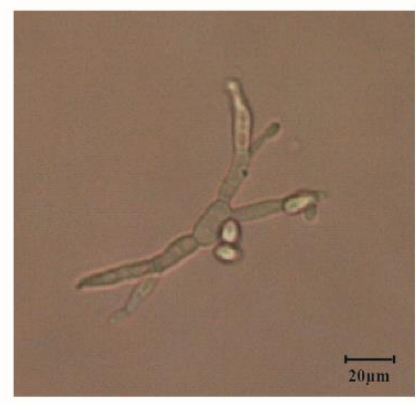

$\Delta V d T H I 20-6$
B

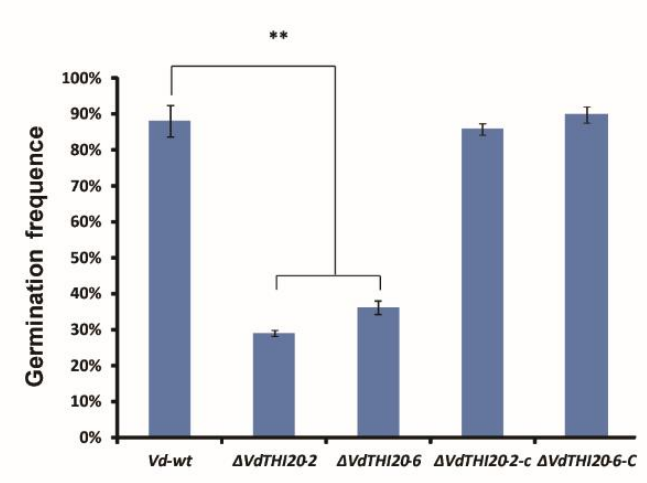

C

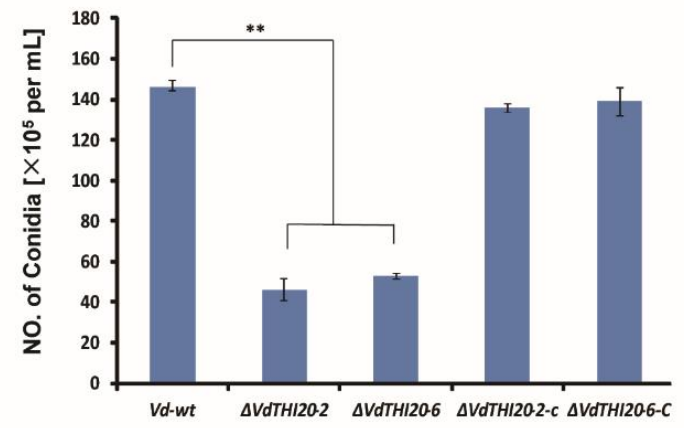

Figure 5. Deletion of VdTHI20 influences hyphal morphology, conidial germination and production. (A) Hyphae of each strain $24 \mathrm{~h}$ after germination in liquid CM broth. The hyphae of the $\Delta V d T H I 20$ strains branched irregularly and did not form whorled branches. The hyphae of the $\Delta V d T H I 20$ strains were also more swollen than those of $V d$ - wt. (B) Percentages of germinated conidia of $V d-w t, \Delta V d T H I 20$ mutant strains ( $\triangle V d T H I 20-2$ and $\Delta V d T H I 20-6)$, and complemented strains ( $\triangle V d T H I 20-2-c$ and $\Delta V d T H I 20-6-c)$ $30 \mathrm{~h}$ after inoculation in liquid CM. Reduced germination frequency of the $\Delta V d T H I 20$ mutant strains in liquid CM in comparison with the $V d$-wt strain is significant while the complemented $\Delta V d T H I 20$ mutant strains in liquid CM in comparison with the $V d$-wt strain is not significant at $30 \mathrm{~h}$. (C) Number of conidia produced by the $V d$-wt strain, $\Delta V d T H I 20$ mutant strains ( $\triangle V d T H I 20-2$ and $\Delta V d T H I 20-6)$, and complemented strains ( $\triangle V$ VTHI20-2-c and $\Delta V d T H I 20-6-c)$ after 15 days on Czapek-Dox agar plates. Decreased number of conidia produced by the $\Delta V d T H I 20$ mutant strains the complemented strains on Czapek-Dox agar plates in comparison to the $V d$-wt strain is significant and not significant after 15 days, respectively. Values represent the mean \pm standard deviation from three independent replicates. Asterisks $\left.{ }^{* *}\right)$ indicate significant differences by Student's $t$ test at $P<0.01$.

\subsection{Loss of VdTHI20 Resulted in Reduced Tolerance to UV Damage}

Thiamine was reported to play a significant role in oxidative stress response [22-26]. The orthologue of HET-P biosynthesis gene THI4, sti35 was reported to play a role in the oxidative stress response in Fusarium oxysporum [27]. VdTHI4 was reported to affect UV damage repair in S. cerevisiae and $V$. dahlia [19]. In addition, $V d \Delta T H I 4$ mutants were susceptible to oxidative stressors menadione and 2,4-DAPG. The $V d \Delta T$ Thit mutants were also susceptible to UV damage and oxidative stressors menadione [20].

The function of $V d T H I 20$ in response to UV radiation stress was evaluated. The number of surviving $\triangle V d T H I 20$ mutant colonies after exposure to UV irradiation was significantly reduced compared with the number of surviving $V d$-wt and complemented strain colonies $(P<0.01)$. This result 
is similar to the previous studies on $\Delta V d T H I 4$ and $V d \Delta T$ Thit [19]. Specifically, only $1.2 \%$ of the UV-treated $\Delta V d T H I 20$ mutant colonies survived UV irradiation at $50 \mathrm{~J} / \mathrm{m}^{2}$, compared with $11.5 \%$ of $V d$-wt colonies (Figure 6).

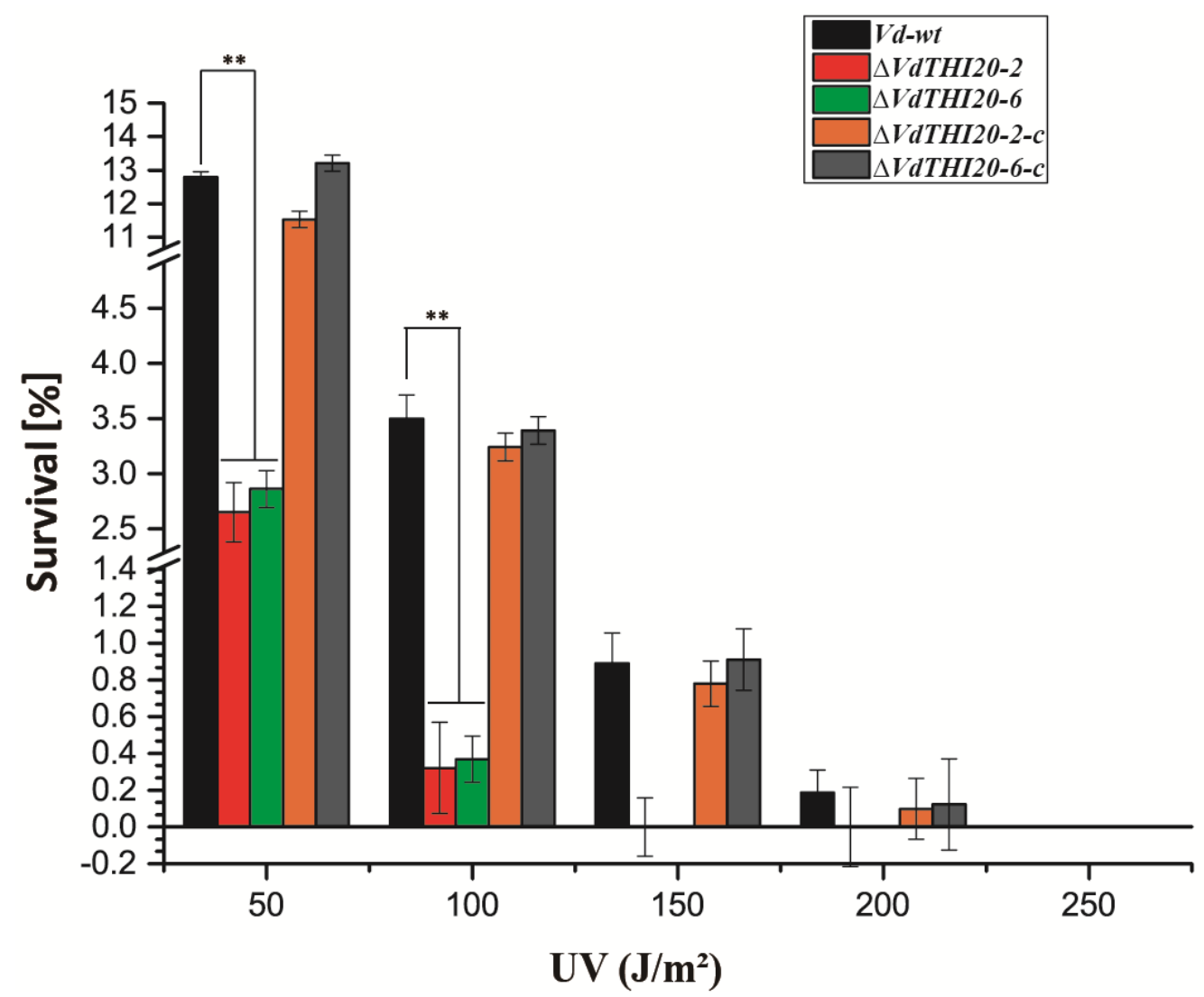

Figure 6. Effect of UV radiation on the growth of the $V d$-wt strain, $\triangle V d T H I 20$ mutant strains ( $\triangle V d T H I 20-2$ and $\Delta V d T H I 20-6)$, and complemented strains ( $\Delta V d T H I 20-2-c$ and $\Delta V d T H I 20-6-c)$. The $\Delta V d T H I 20$ mutant strains were hypersensitive to UV radiation compared with the $V d-w t$ and complemented strains. The percentages of surviving colonies were computed after UV exposure at 50, 100, 150, and $200 \mathrm{~J} / \mathrm{m}^{2}$. The reduction of survival of the $\Delta V d T H I 20$ mutant strain colonies after UV-treatment at 50 and $100 \mathrm{~J} / \mathrm{m}^{2}$ in comparison to that of the $V d$-wt strain is significant. The reduction is restored in the complemented $\Delta V d T H I 20$ mutant strains. Statistical analyses of survival indicated no significant difference between the complemented strains and the $V d$ - $w t$ strain. Values represent the mean \pm standard deviation from three independent replicates. Asterisks $\left({ }^{* *}\right)$ indicate significant differences by Student's $t$ test at $P<0.01$.

\subsection{VdTHI20 Is Crucial for the Pathogenicity of V. dahliae towards Plants}

We then evaluated the VdTHI20 deletion effect on virulence. Wild-type $N$. benthamiana seedlings were inoculated with a conidial suspension of $V d-w t, \triangle V d T H I 20$ mutant strains ( $\triangle V d T H I 20-2$ and $\Delta V d T H I 20-6)$, and complemented strains ( $\triangle V d T H I 20-2-c$ and $\Delta V d T H I 20-6-c)$ by dipping intact roots. At 15 days post-inoculation (dpi), the seedlings infected with the $\Delta V d T H I 20$ mutant strains presented moderate symptoms, with only mild interveinal chlorosis of leaves and nearly no necrosis. In contrast, the seedlings infected with $V d$-wt and the complemented strains displayed typical symptoms, including stunting, chlorosis and wilting, and appeared to be nearly dead (Figure 7A,B). The disease level of N. benthamiana was rescued significantly by VdTHI20 deletion at $5 \mathrm{dpi}, 10 \mathrm{dpi}$ and $15 \mathrm{dpi}$ (Figure 7C). These results are similar to the previous studies on $V d \Delta T h i t$ [19]. In addition, the concentration of fungal DNA amplified from $N$. benthamiana seedlings inoculated with the $\Delta V d T H I 20$ mutant strains was lower than that amplified from the $V d-w t$ and complemented strains (Figure 7D). 


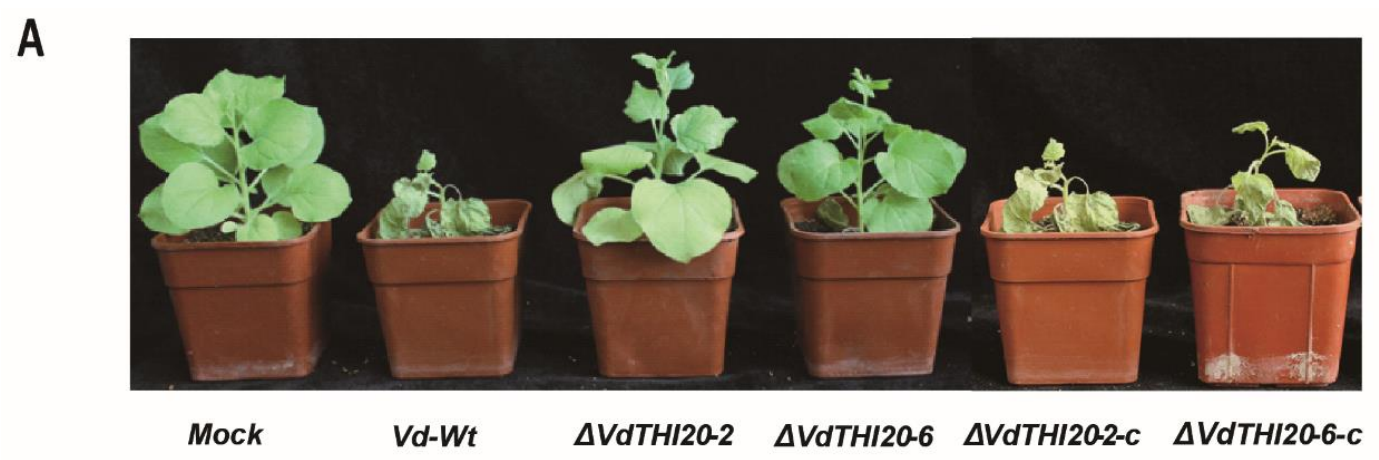

B

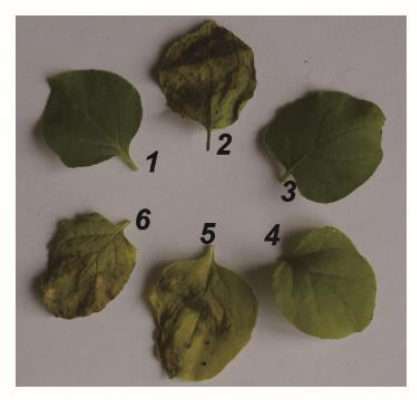

C

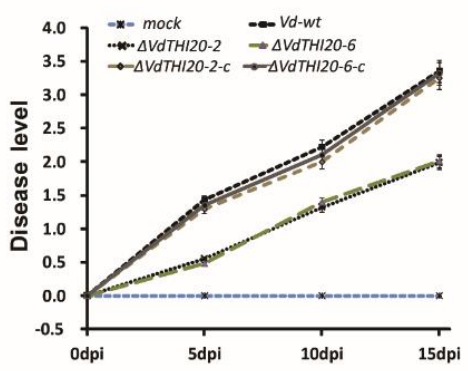

D

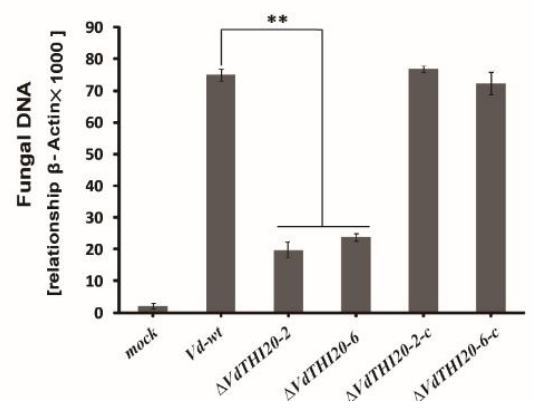

Figure 7. Virulence analysis of the $V d$-wt strain, $\Delta V d T H I 20$ mutant strains $(\Delta V d T H I 20-2$ and $\Delta V d T H I 20-6)$, and complemented $\Delta V d T H I 20$ mutant strains ( $\triangle V d T H I 20-2-c$ and $\Delta V d T H I 20-6-c)$ on $N$. benthamiana. (A) Virulence phenotypes of $N$. benthamiana seedlings at $12 \mathrm{dpi}$ with different $V$. dahliae strains. (B) Representative leaf images of $N$. benthamiana at 12 dpi with different $V$. dahliae strains. 1 , mock; 2, representative leaf of $N$. benthamiana infected with the $V d$-wt strain; 3,4, representative leaf of $N$. benthamiana infected with $\Delta V d T H I 20-2$ and $\Delta V d T H I 20-6$ respectively; 5,6 , representative leaf of $N$. benthamiana infected with $\Delta V d T H I 20-2-c$ and $\Delta V d T H I 20-6-c$ respectively. (C) Disease level of $N$. benthamiana seedlings after a 2-min root dpi in a conidial suspension of the different $V$. dahliae strains at 5, 10, and 15 dpi. (D) Fungal DNA concentration in $N$. benthamiana hypocotyls with different $V$. dahliae strains at $12 \mathrm{dpi}$. N. benthamiana seedlings inoculated with tap water (mock) as a control. The difference of fungal DNA concentration between the $\Delta V d T H I 20$ mutant strains and the $V d$-wt strain is significant. The difference of fungal DNA concentration between the complemented $\Delta V d T H I 20$ mutant strains and the $V d$-wt strain is not significant. Values represent the mean \pm standard deviation from three independent replicates. Asterisks $\left.{ }^{(* *}\right)$ indicate significant differences by Student's $t$ test at $P<0.01$.

\subsection{Fungal Colonization and Root Infection with the $\Delta V d T H I 20$ Mutant Were Impaired}

To investigate fungal colonization and root infection of the $\triangle V d T H I 20$ mutant strains, the GFP-labelled strains $V d \triangle T H I 20-2-G F P$ and $V d$-wt-GFP constitutively expressing eGFP were used. Thus, fungal colonization and penetration were observed under LSCM. Hyphae penetrated the epidermal and vascular system cells with the $V d-w t-G F P$ strain at 3 dpi. Fewer hyphae of the $\triangle V d T H I 20-2-G F P$ mutant strain germinated and colonized $N$. benthamiana roots than the Vd-wt-GFP strain (Figure 8). This result is similar to the previous studies on $V d \Delta T h i t$ [19]. These observations demonstrated that $V d T H I 20$ contributes to fungal penetration and colonization. 


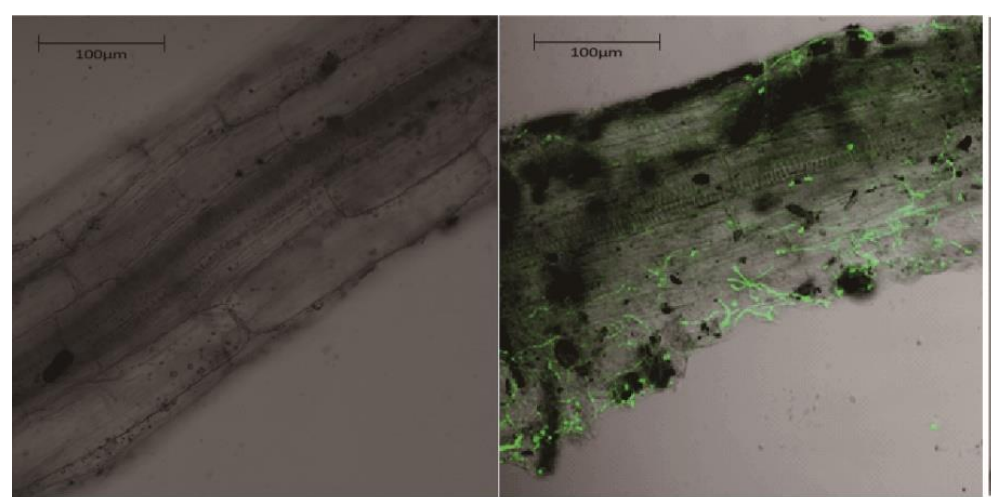

Mock
Vd-Wt-GFP

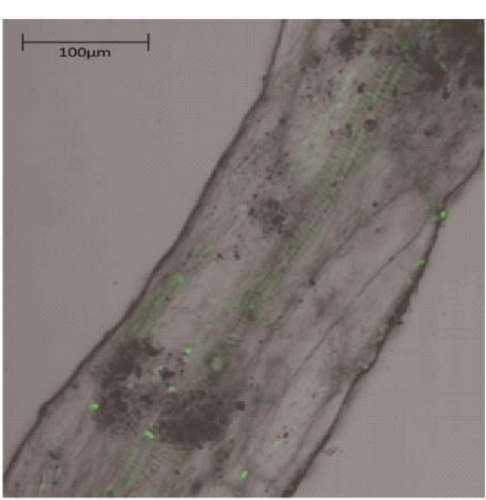

$\triangle$ VdTHI20-2-GFP

Figure 8. Green fluorescent protein (GFP) fluorescence detection of fungal colonization and root infection in N. benthamiana with the Vd-wt-GFP strain, the $\triangle V d T H I 20-2-G F P$ mutant strains, and sterile water (mock) at $3 \mathrm{dpi}$.

2.8. DsRNA of VdTHI20 Confers Resistance Against V. dahliae in Transgenic N. benthamiana Lines

To validate whether dsVdTHI20 plays a role in resistance against $V$. dahliae, wild-type and transgenic $N$. benthamiana lines (RNAi-THI20-3, RNAi-THI20-8 and RNAi-THI20-12) were inoculated with a conidial suspension of $V d-w t$. At $15 \mathrm{dpi}$, the seedlings of wild-type $N$. benthamiana displayed typical symptoms and were nearly dead. In contrast, the seedlings of transgenic $N$. benthamiana lines showed weak symptoms (Figure 9A). The disease level of transgenic N. benthamiana lines was significantly lower than that of wild-type $N$. benthamiana at $5 \mathrm{dpi}, 10 \mathrm{dpi}$, and $15 \mathrm{dpi}$ (Figure 9B). In addition, the concentration of fungal DNA in transgenic $N$. benthamiana lines infected with the conidial suspension of $V d-w t$ was significantly lower than that in wild-type N. benthamiana (Figure 9C). These results indicate that VdTHI20 is required for the pathogenicity of $V$. dahliae. 


\section{A}

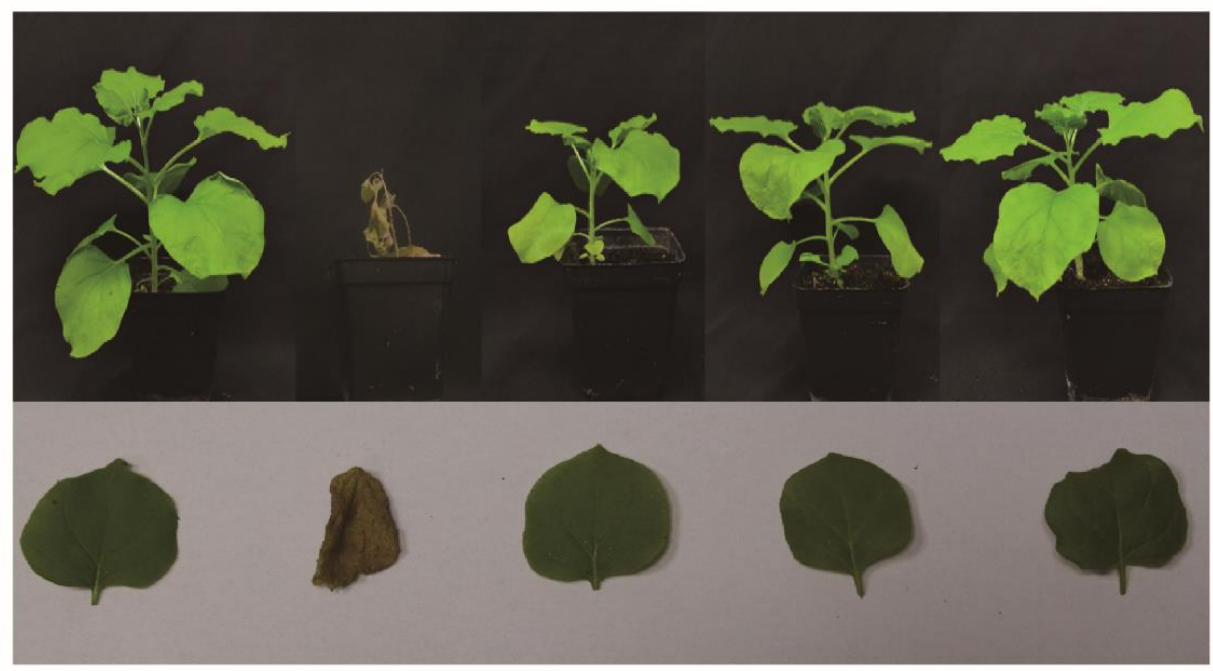

Mock

Wt

RNAi-Thi20-3 RNAi-Thi20-8

RNAi-Thi20-12

\section{B}

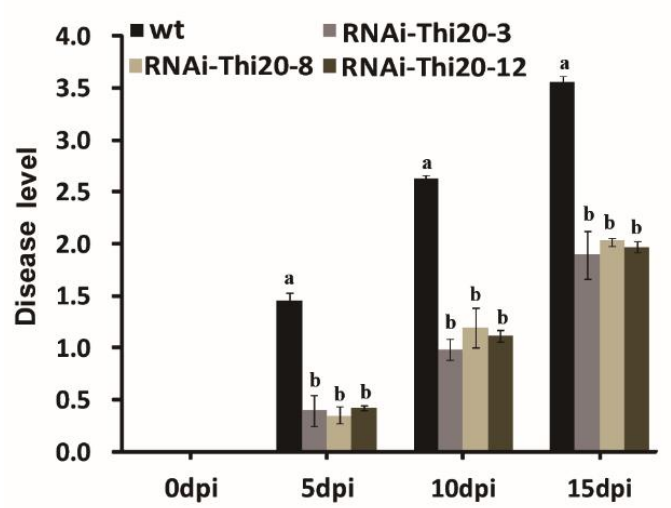

C

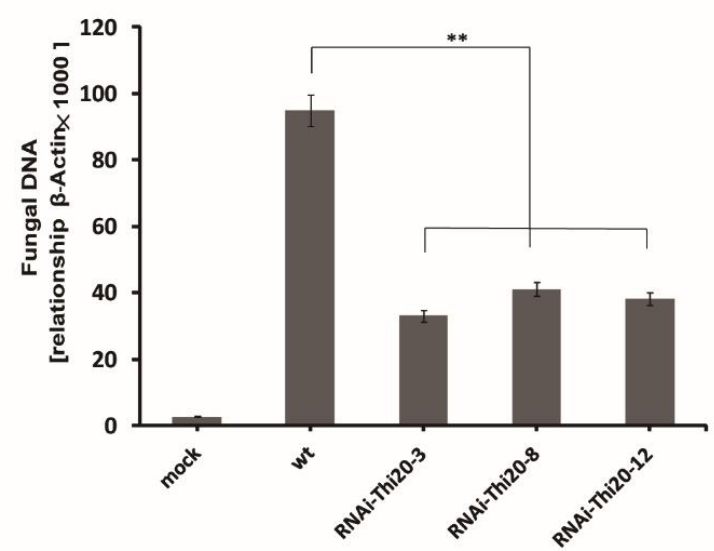

Figure 9. Virulence analysis of the $V d-w t$ strain in wild-type and transgenic $N$. benthamiana lines (RNAi-THI20-3, RNAi-THI20-8, and RNAi-THI20-12). (A) Virulence phenotypes of wild-type and transgenic $N$. benthamiana lines and representative leaves. (B) Disease level of wild-type and transgenic $N$. benthamiana lines after a 2-min root dpi in conidia of $V d-w t$ at 5, 10, and 15 dpi. (C) Fungal DNA concentration in wild-type and transgenic $N$. benthamiana hypocotyls infected with $V d-w t$ at 12 dpi. N. benthamiana seedlings inoculated with tap water (mock) as a control. Values represent the mean \pm standard deviation from three independent replicates. Asterisks $\left({ }^{* *}\right)$ indicate significant differences by Student's $t$ test at $P<0.01$.

\section{Discussion}

Severe losses in cotton production are caused by verticillium wilt every year. Until now, the pathogenesis mechanism has been unclear, making disease control challenging. Verticillium wilt of cotton is caused by $V$. dahliae, a fungal plant pathogen. Thiamine was demonstrated to contribute to fungal pathogenicity based on a previous study [26]. The THI20 family proteins were reported to be involved in the formation of the pyrimidine moiety of thiamine [28]. In our study, we characterized the functions of a member of the THI20 family, VdTHI20, in the pathogenicity of $V$. dahliae. The deletion of VdTHI20 caused a reduction in mycelial growth, conidial germination and production, and UV resistance. The invasion and colonization abilities of $\Delta V d T H I 20$ mutants also decreased. The $\Delta V d T H I 20$ mutant strains exhibited reduced pathogenicity. Together, our research supports that VdTHI20 is necessary for infection by $V$. dahliae. 
Previous studies indicated that VdTHI4 is required for the pathogenicity of $V$. dahliae in tomato. VdTHI4, which is involved in thiazole (a part of thiamine) biosynthesis [29], plays a key role in the conidial growth, infection and colonization of $V$. dahliae. Supplemented thiamine can restore the growth of the $V d \triangle T H I 4$ deletion strain on thiamine-free medium [19]. Another team found that the plasma membrane protein VdThit is also essential for the pathogenicity of $V$. dahliae. This thiamine transporter protein, VdThit, has an important influence on the vegetative growth, conidial germination and production, initial infection and root colonization of $V$. dahliae. By supplementing exogenous thiamine, the defects of $V d \Delta$ Thit mutants in growth, conidiation, and virulence were restored [20]. Similarly, exogenous thiamine restored the growth of $\Delta V d T H I 20$ mutant strains. According to the results of this study and previous studies, $V$. dahliae can use self-synthesized thiamine or uptake thiamine from the environment. These two approaches for thiamine utilization are irreplaceable for the virulence of $V$. dahliae.

The thiamine biosynthesis pathway THI4 gene orthologue sti35 was reported to play a role in the oxidative stress response in Fusarium oxysporum [27]. THI4 affected UV damage repair in $S$. cerevisiae and $V$. dahliae. Additionally, VdSTHI4 exhibited reduced growth on medium with the oxidative stressors menadione and 2,4-DAPG [19]. Fewer colonies of $V d \Delta T h i t$ mutants than of wild type survived after treatment with UV radiation, and $V d \Delta$ Thit mutant strains grew slower than wild type when supplemented with menadione [20]. In accordance with this research, our results showed that $\triangle V d T H I 20$ mutants were more susceptible to UV stress.

Our results indicate that $\Delta V d T H I 20$ has a significant contribution to UV radiation tolerance. Our findings are consistent with previous studies on $\triangle V d T H I 4$ (involved in thiamine synthesis pathway) and $\Delta V d T h i t$ (a thiamine transport protein) mutant strains that could not repair damage from UV radiation $[19,20]$.

RNA interference (RNAi) is a technology using dsRNA to inhibit the expression of target genes [30-32]. In recent years, RNAi has been proven to be a powerful tool to improve the resistance of plants [33-35]. Host-induced gene silencing (HIGS) technology, trans-kingdom RNA silencing, has been developed and applied to protect crops against fungal, pest and viroid infections. Transgenic corn plants harbouring western corn rootworm (WCR) dsRNA were able to control coleopteran pests [36]. RNAi-mediated silencing of OsSSI2 enhanced the resistance to blast and leaf blight in rice [37]. Tomato plants transformed with a viroid hairpin RNA construct showed resistance to potato spindle tuber viroid infection [38]. Expressing dsRNA in tobacco plants improved pest resistance [39]. The silencing of the Foc TR4 ERG6/11 genes increased the resistance of banana to Fusarium wilt [40]. In eggplant, HIGS of Mi-msp-1 improved nematode resistance [41].

$V$. dahliae infects over 200 plant species in nature and has become the most notorious plant vascular pathogen $[5,42]$. Due to its long-term survival in soil and tendency for host vascular colonization, $V$. dahliae is very difficult to control with fungicides, and few plant resistance genes have been identified thus far. For cash crops, such as cotton and sunflower, and major food crops, such as potato, no resistance gene has been identified that efficiently protects plants against $V$. dahliae infection [43]. Based on this fact, HIGS technology has shown promising potential for application against this soilborne fungus [44-48].

Since HIGS has been successfully applied to protect plants against fungal pathogens [49-53], it is not surprising that plants were able to export exogenous artificial sRNAs to target fungal gene transcripts. Subsequently, sRNAs isolated from $V$. dahliae recovered from infected cotton plants were sequenced, and in total, 28 different cotton sRNA sequences were identified. This proved that host-derived sRNAs were indeed transmitted into the fungal pathogen during infection. It was also the first experimental evidence of natural transmission of trans-kingdom RNAi signals from host to fungal pathogen and the cleavage of fungal virulence genes [53]. Researchers have proven that siRNAs and dsRNAs in extracellular vesicles can be efficiently transferred into fungal cells to depress invasion by feeding on plants and parasitism [54].

In this study, transgenic $N$. benthamiana lines expressing dsVdTHI20 exhibited milder disease symptoms and had lower disease levels and less fungal DNA than wild-type N. benthamiana. 
The pathogenesis-related gene VdTHI20 exhibits the potential to control V. dahliae for important crops and provides new insight and a valuable idea for the development of comprehensive management strategies for $V$. dahliae.

\section{Materials and Methods}

\subsection{Fungal Strains, Plant Material and Culture Conditions}

The wild-type $V$. dahliae strain $991(V d-w t)$ is preserved in our laboratory. Complete medium $(\mathrm{CM}, 6 \mathrm{~g} / \mathrm{L}$ yeast extract, $6 \mathrm{~g} / \mathrm{L}$ casein acid hydrolysate, $10 \mathrm{~g} / \mathrm{L}$ sucrose) and Czapek-Dox $(3.0 \mathrm{~g} / \mathrm{L}$ $\mathrm{NaNO}_{3}, 0.5 \mathrm{~g} / \mathrm{L} \mathrm{MgSO} 4 \cdot 7 \mathrm{H}_{2} \mathrm{O}, 0.5 \mathrm{~g} / \mathrm{L} \mathrm{KCl}, 0.01 \mathrm{~g} / \mathrm{L} \mathrm{FeSO}{ }_{4} \cdot 7 \mathrm{H}_{2} \mathrm{O}, 1.0 \mathrm{~g} / \mathrm{L} \mathrm{K}_{2} \mathrm{HPO}_{4}, 15 \mathrm{~g} / \mathrm{L}$ agar) agar were used in this study for the $V d-w t, \triangle V d T H I 20$ mutant and complemented strains. N. benthamiana seedlings were planted in a growth chamber at $23-25^{\circ} \mathrm{C}$ with a photoperiod of $16 \mathrm{~h}$ day $/ 8 \mathrm{~h}$ night and a relative humidity of $60 \%-70 \%$. Agrobacterium tumefaciens AGL1 and the plasmids pGKO2, pCAM-neo, pCM-Hyg, and pCAMgfp were obtained from Prof. Xiaofeng Dai from the Institute of Agro-products Processing Science and Technology, Chinese Academy of Agricultural Sciences in Beijing, China.

\subsection{Plasmid Construction and Fungal Transformation}

For VdTHI20 knockout cassette construction, In-Fusion cloning was used as previously described [55]. The neomycin phosphotransferase resistance (neo) cassette was amplified from pCAM-neo using the primer pair neo-F and neo-R (Table 2). The $1197 \mathrm{bp} 5^{\prime}$ upstream sequence and $1108 \mathrm{bp} \mathrm{3'}$ downstream sequence of $V d T H I 20$ were amplified from the $V d$-wt strain genome with the primer pairs VdTHI20-5F and VdTHI20-5R and VdTHI20-3F and VdTHI20-3R, respectively (Table 2). For In-Fusion cloning, the vector pGKO2 was digested with EcoRI or HindIII to create linearized pGKO2 (Figure 2A). According to the specifications of the In-Fusion dry-down PCR cloning kit (Clontech, Mountain View, CA, USA), the linearized vector together with three amplicons, the neo cassette, the $5^{\prime}$ upstream fragment and the $3^{\prime}$ downstream fragment, were fused to generate the pGn-VdTHI20 plasmid pGKO2 [EcoRI]::VdTHI20-5'::neo::VdTHI20-3'::pGKO2 [HindIII]. All the constructs were verified by enzymatic identification and DNA sequencing (Sangon, Shanghai, China).

The VdTHI20 complementary vector PCM-Hyg-VdTHI20 was generated using the same method. The pCM-Hyg vector with the hygromycin B resistance gene $(h p h)$ cassette was digested with the enzymes KpnI and XbaI. Three fragments, full-length VdTHI20 cDNA, the TrpC promoter and the Nos terminator, were individually amplified with the primer pairs C-VdTHI20-F and C-VdTHI20-R, C-TrpC-F and C-TrpC-R and C-Nos-F and C-Nos-R (Table 2). All three amplicons were inserted into a digested $\mathrm{pCM}-\mathrm{Hyg}$ vector with In-Fusion enzyme.

The constructs pGn-VdTHI20 were introduced into A. tumefaciens AGL1 using electroporation. Agrobacterium tumefaciens-mediated transformation (ATMT) was used as described previously [56]. The homologous recombination transformants were selected on PDA medium (potato, $200 \mathrm{~g} / \mathrm{L}$, glucose, $20 \mathrm{~g} / \mathrm{L}$, agar, $15 \mathrm{~g} / \mathrm{L}$ ) with $200 \mu \mathrm{g} / \mathrm{mL}$ of cefotaxime, $50 \mu \mathrm{g} / \mathrm{mL}$ of $\mathrm{G} 418$ and $200 \mu \mathrm{g} / \mathrm{mL}$ of 5-fluoro-2'-deoxyuridine. The complemented transformants were screened on the PDA medium with $200 \mu \mathrm{g} / \mathrm{mL}$ of cefotaxime and $50 \mu \mathrm{g} / \mathrm{mL}$ of hygromycin, in addition to $100 \mu \mathrm{g} / \mathrm{mL}$ geneticin for complementary transformants of VdTHI20 deletion mutants. Likewise, the plasmid pCAMgfp containing the enhanced green fluorescent protein (eGFP) and $h p h$ genes was introduced into the $V d-w t$ strain and the $\Delta V d T H I 20$ mutant strains using the same method. The single spore isolation was performed for all transformants, and the positive transformants were verified by PCR with the test primers (Table 2). 
Table 2. Primers used in this study.

\begin{tabular}{ll}
\hline & \multicolumn{1}{c}{ Primer Name $^{\prime}$ equences $\left(\mathbf{5}^{\prime} \rightarrow \mathbf{3}^{\prime} \mathbf{)}\right.$} \\
\hline Thi20-5F & GTACCCAATTCGAATC ATTGTGTTGAGGAGGACACCGAT \\
Thi20-5R & CAAGACAGCCCGCAAAC TCTCCTTGAGAAAACGAGTGA \\
Thi20-3F & CCCAGAATGCACAGGT TGTTGATGTCGGTGTCATCGTC \\
Thi20-3R & GACGGTATCGATAAGCTT TGTTGGAAAAAGGTCAGTCAT \\
C-TrpC-F & TTGAAGGAGCATTTTTGGC \\
C-TrpC-R & ATCGATGCTTGGGTAGAATAGGT \\
C-VdThi20-F & AAAAGTACTATGGCACAGCAGATGGGCCG \\
C-VdThi20-R & AAACTGCAGTCTACTGGCACGGGAACATCT \\
C-Nos-F & AGATGCCGACCGGGATCCACTT \\
C-Nos-R & TTATCTTTGCGAACCCAGGG \\
neo-F & GTTTGCGGGCTGTCTTGACG \\
neo-R & TACCTGTGCATTCTGGGTAA \\
Thi20-J-F & GCGCAGGACACAAAGGGCGT \\
Thi20-J-R & AGCGTGCCGTTGCCGAGACC \\
noe-J-F & ATGATTGAACAAGATGGATT \\
noe-J-R & TCAGAAGAACTCGTCAAGAA \\
Thit-F & CTCGTGACTTTATCGGGTTTCT \\
Thit-R & GGCGGATGAGCTGGAATTAT \\
VdBt-F & TTCCCCCGTCTCCACTTCTTCATG \\
VdBt-R & GACGAGATCGT TCATGTTGAACTC \\
Nb-actin-F & GGACCTTTATGGAAACATTGTGCTCAGT \\
Nb-actin-R & CCAAGATAGAACCTCCAATCCAGACAC \\
Vd-F & CCGCCGGTCCATCAGTCTCTCTGTTTATAC \\
Vd-R & CGCCTGCGGGACTCCGATGCGAGCTGTAAC \\
TransThi20F & GGGGACAAGTTTGTACAAAAAAGCAGGCTCGCAACCATTGTCAAGCACA \\
TransThi20R & GGGGACCACTTTGTACAAGAAAGCTGGGTTTCCAGTACACGTTGCCCTC \\
\hline
\end{tabular}

4.3. Confirmation of VdTHI20 Gene Disruption or the Complementation of $\triangle V d T H I 20$ and Screening for GFP-tagged Strains

The primer pairs VdTHI20-J-F and VdTHI20-J-R were used to examine the neo cassette of the VdTHI20 knockout mutants (Table 2). Complemented strains were checked by PCR using the primer pairs VdTHI20-J-F and VdTHI20-J-R and hyg-F and hyg-R (Table 2). Additionally, GFP-labelled strains were screened for the $h p h$ gene using the primer pair hyg-F and hyg-R. GFP fluorescence was observed under a laser confocal scanning microscope (LSCM; LSM700, Zeiss, Jena, Germany).

\subsection{Growth, Conidia Production, and Germination Assays}

The colony diameter and morphology of the $V d$-wt strain, $\Delta V d T H I 20$ mutant strains, and complemented $\triangle V d T H I 20$ strains were recorded every 2 to 3 days on minimal medium (MM) agar $\left(6 \mathrm{~g} / \mathrm{L} \mathrm{NaNO} 3,0.52 \mathrm{~g} / \mathrm{L} \mathrm{KCl}, 0.152 \mathrm{~g} / \mathrm{L} \mathrm{MgSO} 4,1.52 \mathrm{~g} / \mathrm{L} \mathrm{KH}_{2} \mathrm{PO}_{4}, 0.01 \mathrm{~g} / \mathrm{L}\right.$ thiamine, $10 \mathrm{~mL} / \mathrm{L}$ trace elements, and $15 \mathrm{~g} / \mathrm{L}$ agar) amended with different carbon sources $(10 \mathrm{~g} / \mathrm{L}$ pectin, $10 \mathrm{~g} / \mathrm{L}$ galactose, $10 \mathrm{~g} / \mathrm{L}$ xylose, $10 \mathrm{~g} / \mathrm{L}$ starch, or $30 \mathrm{~g} / \mathrm{L}$ sucrose) [57].

For conidia production tests, conidial suspension $\left(1 \mathrm{~mL}, 5 \times 10^{6}\right.$ conidia/mL) of $V d$-wt strain, $\triangle$ VdTHI20 mutant strains and complemented strains were added to $200 \mathrm{~mL}$ Czapek-Dox broth in sterile conical flasks. After 6 days on a shaker with $180 \mathrm{rpm}$ at $25^{\circ} \mathrm{C}$, the suspension was filtered through a cell strainer, and then the conidia were counted using a hemacytometer and a light microscope. Conidia production was then calculated as previously described [58]. Each assay was repeated three times.

For germination tests, the germination of all $V$. dahliae strains was calculated as described previously [59]. The conidial suspension of $V d$-wt strain, $\Delta V d T H I 20$ mutant strains and complemented $\triangle V$ dTHI20 mutant strains were cultured in CM broth, and then shaken for $12 \mathrm{~h}$ with $140 \mathrm{rpm}$ at $25^{\circ} \mathrm{C}$. Samples were examined at $2 \mathrm{~h}$ intervals and germination rate was determined by counting 100 conidia. Each assay was repeated three times. 


\subsection{Phenotypic Analysis under Stress Conditions}

Conidial suspensions of each strain, the $V d$-wt strain, $\Delta V d T H I 20$ mutant strains, and complemented strains, were spread onto Czapek-Dox agar and incubated at $25^{\circ} \mathrm{C}$ for $1 \mathrm{~h}$. For UV light treatment, conidia from each strain were placed under UV radiation at 50,100, 150, and $200 \mathrm{~J} / \mathrm{m}^{2}$ with a UV Crosslinker Spectrolinker XL-1000A (Spectronics Corp., Westbury, NY, U.S.A.), after which the conidia were incubated at $25^{\circ} \mathrm{C}$ for three days. Colonies were enumerated on each plate. The experiment was repeated three times.

\subsection{Quantitative Real-Time PCR ( $q R T-P C R)$}

The expression level of the gene VdThit (VDAG_03620) encoding a thiamine transport protein was measured in the $V d$-wt strain, $\Delta V d T H I 20$ mutant strains, and complemented $\Delta V d T H I 20-c$ strains. Total RNA was extracted from each $V$. dahliae strain using the RNA miniprep kit (Axygen, Union City, CA, USA) according to the manufacturer's instructions. cDNAs were synthesized using a Toyobo RT kit (Osaka, Japan). qRT-PCR was performed with the SYBR Fast qPCR kit (Kapa Biosystems, Boston, MA, USA). The expression level of VdThit was quantified using the $\beta$-tubulin gene (DQ266153) as an internal reference, which was amplified with the primer pair VdThit-F and VdThit-R (Table 2). The qRT-PCRs were performed on an ABI QuantStudio 6 flex PCR thermocycler (Applied Biosystems, Foster City, CA, USA) and repeated three times.

\subsection{Hyphal Growth under Different Concentrations of Exogenous Thiamine}

The colony diameter, conidia production, and virulence of the $\Delta V d T H I 20$ mutant strains were characterized as described above. No thiamine or 0.2 to $2 \mathrm{mg} / \mathrm{L}$ exogenous thiamine was added to each Czapek-Dox agar plate. The assay was repeated three times independently.

\subsection{Microscopic Observation of Initial Infection}

For microscopically observing initial infection, roots of $N$. benthamiana seedlings with 6-7 true leaves were infected with the $V d$-wt-GFP strain and the VdDTHI20-2-GFP mutant strain. After 3 days, the infected slices of $N$. benthamiana roots were observed under LSCM. The assay was repeated three times independently.

\subsection{Plasmid Construction and Plant Transformation}

The primer pair was designed based on the THI20 ORF (Trans-THI20, Table 2). The partial BP adaptors were used for targeted fragment amplification. The whole sequence was amplified with BP site primers, followed by inserting into the pDONR207 vector by a BP recombination reaction (Invitrogen, Carlsbad, CA, USA). The targeted fragment was then inserted into the pK7GWIWG2(I) vector to obtain pK7GW12WG2-THI20 by an LR recombination reaction (Invitrogen, Carlsbad, CA, USA). The resulting plasmid was confirmed by sequencing, followed by transforming into Agrobacterium tumefaciens strain LBA4404 by electroporation.

Seeds of $N$. benthamiana were grown on MS agar. After 30 days, sterile leaves were immersed in a solution of A. tumefaciens strain LBA4404 with the recombinant plasmid and cultured on MS agar plates subsequently. After 3 days, the leaves were transferred to MS agar plates with $100 \mathrm{mg} / \mathrm{L}$ kanamycin.

Author Contributions: Q.W. and T.Q. conceived and designed the research; C.W., J.S., and T.D. participated in data analysis and material collection; W.W., Q.Y., Y.Z., and S.Y. participated in morphological experiments; Y.L., N.D., R.S., Y.W., and B.W. constructed the plasmids for complementation, obtained the complemented strains and revised the manuscript; T.Q. and W.H. performed most of the experiments and wrote the manuscript. All authors have read and agreed to the published version of the manuscript.

Funding: This research was supported by the National Natural Key Research Development Program of China (2016YFD0101413), the National Natural Science Foundation of China (Project: 31170263), Major Science and Technology Projects in Henan Province (Project: 161100510100) and the Science and Technique Foundation Project of Henan Province (182102110003). 
Conflicts of Interest: The authors declare no conflict of interest.

\author{
Abbreviations \\ ATMT Agrobacterium tumefaciens-mediated transformation \\ GFP green fluorescent protein \\ RNAi RNA interference \\ HIGS host induced gene scilencing \\ dpi days post-inoculation \\ MM minimal medium \\ wt wild type \\ HMP 2-methyl-4-amino-5-hydroxymethylpyrimidine \\ HET 4-methyl-5- $\beta$-hydroxyethylthiazole \\ TPP phosphorylated thiamine
}

\title{
References
}

1. Fradin, E.F.; Thomma, B.P. Physiology and molecular aspects of Verticillium wilt diseases caused by V. dahliae and V. albo-atrum. Mol. Plant Pathol. 2006, 7, 71-86. [CrossRef]

2. Deketelaere, S.; Tyvaert, L.; Franca, S.C.; Hofte, M. Desirable Traits of a Good Biocontrol Agent against Verticillium Wilt. Front. Microbiol. 2017, 8, 1186. [CrossRef]

3. Tang, Y.; Zhang, Z.; Lei, Y.; Hu, G.; Liu, J.; Hao, M.; Chen, A.; Peng, Q.; Wu, J. Cotton WATs Modulate SA Biosynthesis and Local Lignin Deposition Participating in Plant Resistance Against Verticillium dahliae. Front. Plant Sci. 2019, 10, 526. [CrossRef] [PubMed]

4. Cai, Y.F.; He, X.H.; Mo, J.C.; Sun, Q.; Yang, J.P.; Liu, J.G. Molecular research and genetic engineering of resistance to Verticillium wilt in cotton: A review. Afr. J. Biotechnol. 2009, 8, 7363-7372.

5. Klosterman, S.J.; Subbarao, K.V.; Kang, S.; Veronese, P.; Gold, S.E.; Thomma, B.P.; Chen, Z.; Henrissat, B.; Lee, Y.H.; Park, J.; et al. Comparative genomics yields insights into niche adaptation of plant vascular wilt pathogens. PLoS Pathog. 2011, 7, e1002137. [CrossRef] [PubMed]

6. Klimes, A.; Dobinson, K.F.; Thomma, B.P.; Klosterman, S.J. Genomics spurs rapid advances in our understanding of the biology of vascular wilt pathogens in the genus Verticillium. Annu. Rev. Phytopathol. 2015, 53, 181-198. [CrossRef]

7. Iosue, C.L.; Attanasio, N.; Shaik, N.F.; Neal, E.M.; Leone, S.G.; Cali, B.J.; Peel, M.T.; Grannas, A.M.; Wykoff, D.D. Partial Decay of Thiamine Signal Transduction Pathway Alters Growth Properties of Candida glabrata. PLoS ONE 2016, 11, e0152042. [CrossRef]

8. Kawasaki, Y.; Nosaka, K.; Kaneko, Y.; Nishimura, H.; Iwashima, A. Regulation of thiamine biosynthesis in Saccharomyces cerevisiae. J. Bacteriol. 1990, 172, 6145-6147. [CrossRef]

9. Jurgenson, C.T.; Begley, T.P.; Ealick, S.E. The structural and biochemical foundations of thiamin biosynthesis. Annu. Rev. Biochem. 2009, 78, 569-603. [CrossRef]

10. Wightman, R.; Meacock, P.A. The THI5 gene family of Saccharomyces cerevisiae: Distribution of homologues among the hemiascomycetes and functional redundancy in the aerobic biosynthesis of thiamin from pyridoxine. Microbiology 2003, 149, 1447-1460. [CrossRef]

11. Llorente, B.; Fairhead, C.; Dujon, B. Genetic redundancy and gene fusion in the genome of the Baker's yeast Saccharomyces cerevisiae: Functional characterization of a three-member gene family involved in the thiamine biosynthetic pathway. Mol. Microbiol. 1999, 32, 1140-1152. [CrossRef] [PubMed]

12. Kawasaki, Y.; Onozuka, M.; Mizote, T.; Nosaka, K. Biosynthesis of hydroxymethylpyrimidine pyrophosphate in Saccharomyces cerevisiae. Curr. Genet. 2005, 47, 156-162. [CrossRef] [PubMed]

13. French, J.B.; Begley, T.P.; Ealick, S.E. Structure of trifunctional THI20 from yeast. Acta Crystallogr. Sect. D Biol. Crystallogr. 2011, 67, 784-791. [CrossRef] [PubMed]

14. Machado, C.R.; Praekelt, U.M.; de Oliveira, R.C.; Barbosa, A.C.; Byrne, K.L.; Meacock, P.A.; Menck, C.F. Dual role for the yeast THI4 gene in thiamine biosynthesis and DNA damage tolerance. J. Mol. Biol. 1997, 273, 114-121. [CrossRef] 
15. Nosaka, K.; Nishimura, H.; Kawasaki, Y.; Tsujihara, T.; Iwashima, A. Isolation and characterization of the THI6 gene encoding a bifunctional thiamin-phosphate pyrophosphorylase/hydroxyethylthiazole kinase from Saccharomyces cerevisiae. J. Biol. Chem. 1994, 269, 30510-30516.

16. Nosaka, K.; Kaneko, Y.; Nishimura, H.; Iwashima, A. Isolation and characterization of a thiamin pyrophosphokinase gene, THI80, from Saccharomyces cerevisiae. J. Biol. Chem. 1993, 268, 17440-17447.

17. Enjo, F.; Nosaka, K.; Ogata, M.; Iwashima, A.; Nishimura, H. Isolation and characterization of a thiamin transport gene, THI10, from Saccharomyces cerevisiae. J. Biol. Chem. 1997, 272, 19165-19170. [CrossRef]

18. Nosaka, K.; Kaneko, Y.; Nishimura, H.; Iwashima, A. A possible role for acid phosphatase with thiamin-binding activity encoded by PHO3 in yeast. Fems Microbiol. Lett. 1989, 51, 55-59. [CrossRef]

19. Hoppenau, C.E.; Tran, V.-T.; Kusch, H.; Aßhauer, K.P.; Landesfeind, M.; Meinicke, P.; Popova, B.; Braus-Stromeyer, S.A.; Braus, G.H. Verticillium dahliae VdTHI4, involved in thiazole biosynthesis, stress response and DNA repair functions, is required for vascular disease induction in tomato. Environ. Exp. Bot. 2014, 108, 14-22. [CrossRef]

20. Qi, X.; Su, X.; Guo, H.; Qi, J.; Cheng, H. VdThit, a Thiamine Transport Protein, Is Required for Pathogenicity of the Vascular Pathogen Verticillium dahliae. Mol. Plant-Microbe Interact. Mpmi 2016, 29, 545-559. [CrossRef]

21. Haas, A.L.; Laun, N.P.; Begley, T.P. Thi20, a remarkable enzyme from Saccharomyces cerevisiae with dual thiamin biosynthetic and degradation activities. Bioorganic Chem. 2005, 33, 338-344. [CrossRef] [PubMed]

22. Ahn, I.P.; Kim, S.; Lee, Y.H. Vitamin B1 functions as an activator of plant disease resistance. Plant Physiol. 2005, 138, 1505-1515. [CrossRef] [PubMed]

23. Rapala-Kozik, M.; Kowalska, E.; Ostrowska, K. Modulation of thiamine metabolism in Zea mays seedlings under conditions of abiotic stress. J. Exp. Bot. 2008, 59, 4133-4143. [CrossRef] [PubMed]

24. Rapala-Kozik, M.; Wolak, N.; Kujda, M.; Banas, A.K. The upregulation of thiamine (vitamin B1) biosynthesis in Arabidopsis thaliana seedlings under salt and osmotic stress conditions is mediated by abscisic acid at the early stages of this stress response. BMC Plant Biol. 2012, 12, 2. [CrossRef] [PubMed]

25. Tunc-Ozdemir, M.; Miller, G.; Song, L.; Kim, J.; Sodek, A.; Koussevitzky, S.; Misra, A.N.; Mittler, R.; Shintani, D. Thiamin confers enhanced tolerance to oxidative stress in Arabidopsis. Plant Physiol. 2009, 151, 421-432. [CrossRef]

26. Goyer, A. Thiamine in plants: Aspects of its metabolism and functions. Phytochemistry 2010, 71, 1615-1624. [CrossRef]

27. Ruiz-Roldan, C.; Puerto-Galan, L.; Roa, J.; Castro, A.; Di Pietro, A.; Roncero, M.I.; Hera, C. The Fusarium oxysporum sti35 gene functions in thiamine biosynthesis and oxidative stress response. Fungal Genet. Biol. 2008, 45, 6-16. [CrossRef]

28. Onozuka, M.; Konno, H.; Kawasaki, Y.; Akaji, K.; Nosaka, K. Involvement of thiaminase II encoded by the THI20 gene in thiamin salvage of Saccharomyces cerevisiae. Fems Yeast Res. 2008, 8, 266-275. [CrossRef]

29. Jurgenson, C.T.; Chatterjee, A.; Begley, T.P.; Ealick, S.E. Structural insights into the function of the thiamin biosynthetic enzyme Thi4 from Saccharomyces cerevisiae. Biochemistry 2006, 45, 11061-11070. [CrossRef]

30. Tijsterman, M.; Ketting, R.F.; Plasterk, R.H. The genetics of RNA silencing. Annu. Rev. Genet. 2002, 36, 489-519. [CrossRef]

31. Hannon, G.J. RNA interference. Nature 2002, 418, 244-251. [CrossRef]

32. Baulcombe, D. RNA silencing. Trends Biochem. Sci. 2005, 30, 290-293. [CrossRef]

33. Younis, A.; Siddique, M.I.; Kim, C.K.; Lim, K.B. RNA Interference (RNAi) Induced Gene Silencing: A Promising Approach of Hi-Tech Plant Breeding. Int. J. Biol. Sci. 2014, 10, 1150-1158. [CrossRef]

34. Fang, X.; Qi, Y. RNAi in Plants: An Argonaute-Centered View. Plant Cell 2016, 28, 272-285. [CrossRef]

35. Mamta, B.; Rajam, M.V. RNAi technology: A new platform for crop pest control. Physiol. Mol. Biol. Plants: Int. J. Funct. Plant Biol. 2017, 23, 487-501. [CrossRef]

36. Baum, J.A.; Bogaert, T.; Clinton, W.; Heck, G.R.; Feldmann, P.; Ilagan, O.; Johnson, S.; Plaetinck, G.; Munyikwa, T.; Pleau, M.; et al. Control of coleopteran insect pests through RNA interference. Nat. Biotechnol. 2007, 25, 1322-1326. [CrossRef]

37. Jiang, C.J.; Shimono, M.; Maeda, S.; Inoue, H.; Mori, M.; Hasegawa, M.; Sugano, S.; Takatsuji, H. Suppression of the rice fatty-acid desaturase gene OsSSI2 enhances resistance to blast and leaf blight diseases in rice. Mol. Plant-Microbe Interact. 2009, 22, 820-829. [CrossRef] 
38. Schwind, N.; Zwiebel, M.; Itaya, A.; Ding, B.; Wang, M.B.; Krczal, G.; Wassenegger, M. RNAi-mediated resistance to Potato spindle tuber viroid in transgenic tomato expressing a viroid hairpin RNA construct. Mol. Plant Pathol. 2009, 10, 459-469. [CrossRef]

39. Zhu, J.Q.; Liu, S.; Ma, Y.; Zhang, J.Q.; Qi, H.S.; Wei, Z.J.; Yao, Q.; Zhang, W.Q.; Li, S. Improvement of pest resistance in transgenic tobacco plants expressing dsRNA of an insect-associated gene EcR. PLoS ONE 2012, 7, e38572. [CrossRef]

40. Dou, T.; Shao, X.; Hu, C.; Liu, S.; Sheng, O.; Bi, F.; Deng, G.; Ding, L.; Li, C.; Dong, T.; et al. Host-induced gene silencing of Foc TR4 ERG6/11 genes exhibits superior resistance to Fusarium wilt of banana. Plant Biotechnol. J. 2019. [CrossRef]

41. Chaudhary, S.; Dutta, T.K.; Tyagi, N.; Shivakumara, T.N.; Papolu, P.K.; Chobhe, K.A.; Rao, U. Host-induced silencing of Mi-msp-1 confers resistance to root-knot nematode Meloidogyne incognita in eggplant. Transgenic Res. 2019, 28, 327-340. [CrossRef]

42. Inderbitzin, P.; Bostock, R.M.; Davis, R.M.; Usami, T.; Platt, H.W.; Subbarao, K.V. Phylogenetics and taxonomy of the fungal vascular wilt pathogen Verticillium, with the descriptions of five new species. PLoS ONE 2011, 6, e28341. [CrossRef]

43. DeVay, J.E.; Weir, B.L.; Wakeman, R.J.; Stapleton, J.J. Effects of Verticillium dahliae Infection of Cotton Plants (Gossypium hirsutum) on Potassium Levels in Leaf Petioles. Plant Dis. 1997, 81, 1089-1092. [CrossRef]

44. Zhang, T.; Zhao, Y.L.; Zhao, J.H.; Wang, S.; Jin, Y.; Chen, Z.Q.; Fang, Y.Y.; Hua, C.L.; Ding, S.W.; Guo, H.S. Cotton plants export microRNAs to inhibit virulence gene expression in a fungal pathogen. Nat. Plants 2016, 2, 16153. [CrossRef]

45. Su, X.; Rehman, L.; Guo, H.; Li, X.; Zhang, R.; Cheng, H. AAC as a Potential Target Gene to Control Verticillium dahliae. Genes 2017, 8, 25. [CrossRef]

46. Su, X.; Rehman, L.; Guo, H.; Li, X.; Cheng, H. The oligosaccharyl transferase subunit STT3 mediates fungal development and is required for virulence in Verticillium dahliae. Curr. Genet. 2018, 64, 235-246. [CrossRef]

47. Wang, J.; Tian, L.; Zhang, D.D.; Short, D.P.G.; Zhou, L.; Song, S.S.; Liu, Y.; Wang, D.; Kong, Z.Q.; Cui, W.Y.; et al. SNARE-Encoding Genes VdSec22 and VdSso1 Mediate Protein Secretion Required for Full Virulence in Verticillium dahliae. Mol. Plant-Microbe Interact. 2018, 31, 651-664. [CrossRef]

48. Song, Y.; Thomma, B. Host-induced gene silencing compromises Verticillium wilt in tomato and Arabidopsis. Mol. Plant Pathol. 2018, 19, 77-89. [CrossRef]

49. Nowara, D.; Gay, A.; Lacomme, C.; Shaw, J.; Ridout, C.; Douchkov, D.; Hensel, G.; Kumlehn, J.; Schweizer, P. HIGS: Host-induced gene silencing in the obligate biotrophic fungal pathogen Blumeria graminis. Plant Cell 2010, 22, 3130-3141. [CrossRef]

50. Panwar, V.; McCallum, B.; Bakkeren, G. Host-induced gene silencing of wheat leaf rust fungus Puccinia triticina pathogenicity genes mediated by the Barley stripe mosaic virus. Plant Mol. Biol. 2013, 81, 595-608. [CrossRef]

51. Koch, A.; Biedenkopf, D.; Furch, A.; Weber, L.; Rossbach, O.; Abdellatef, E.; Linicus, L.; Johannsmeier, J.; Jelonek, L.; Goesmann, A.; et al. An RNAi-Based Control of Fusarium graminearum Infections Through Spraying of Long dsRNAs Involves a Plant Passage and Is Controlled by the Fungal Silencing Machinery. PLoS Pathog. 2016, 12, e1005901. [CrossRef] [PubMed]

52. Wang, M.; Weiberg, A.; Lin, F.M.; Thomma, B.P.H.J.; Huang, H.D.; Jin, H.L. Bidirectional cross-kingdom RNAi and fungal uptake of external RNAs confer plant protection. Nat. Plants 2016, 2. [CrossRef]

53. Zhang, T.; Jin, Y.; Zhao, J.H.; Gao, F.; Zhou, B.J.; Fang, Y.Y.; Guo, H.S. Host-Induced Gene Silencing of the Target Gene in Fungal Cells Confers Effective Resistance to the Cotton Wilt Disease Pathogen Verticillium dahliae. Mol. Plant 2016, 9, 939-942. [CrossRef] [PubMed]

54. Cai, Q.; Qiao, L.; Wang, M.; He, B.; Lin, F.M.; Palmquist, J.; Huang, S.D.; Jin, H. Plants send small RNAs in extracellular vesicles to fungal pathogen to silence virulence genes. Science 2018, 360, 1126-1129. [CrossRef] [PubMed]

55. Irwin, C.R.; Farmer, A.; Willer, D.O.; Evans, D.H. In-Fusion ${ }^{\circledR}$ Cloning with Vaccinia Virus DNA Polymerase. In Vaccinia Virus and Poxvirology: Methods and Protocols; Isaacs, S.N., Ed.; Humana Press: Totowa, NJ, USA, 2012; pp. 23-35.

56. Mullins, E.D.; Chen, X.; Romaine, P.; Raina, R.; Geiser, D.M.; Kang, S. Agrobacterium-Mediated Transformation of Fusarium oxysporum: An Efficient Tool for Insertional Mutagenesis and Gene Transfer. Phytopathology 2001, 91, 173-180. [CrossRef] [PubMed] 
57. Tzima, A.K.; Paplomatas, E.J.; Rauyaree, P.; Ospina-Giraldo, M.D.; Kang, S. VdSNF1, the sucrose nonfermenting protein kinase gene of Verticillium dahliae, is required for virulence and expression of genes involved in cell-wall degradation. Mol. Plant-Microbe Interact. 2011, 24, 129-142. [CrossRef]

58. Qi, X.; Su, X.; Guo, H.; Qi, J.; Cheng, H. A ku70 null mutant improves gene targeting frequency in the fungal pathogen Verticillium dahliae. World J. Microbiol. Biotechnol. 2015, 31, 1889-1897. [CrossRef]

59. Tzima, A.K.; Paplomatas, E.J.; Tsitsigiannis, D.I.; Kang, S. The G protein beta subunit controls virulence and multiple growth- and development-related traits in Verticillium dahliae. Fungal Genet. Biol. 2012, 49, 271-283. [CrossRef]

(C) 2020 by the authors. Licensee MDPI, Basel, Switzerland. This article is an open access article distributed under the terms and conditions of the Creative Commons Attribution (CC BY) license (http://creativecommons.org/licenses/by/4.0/). 